\title{
Peak load pricing with heterogeneous technology: The off-peakers too bear the capacity cost
}

\author{
Vijayamohanan Pillai N. \\ Centre for Development Studies, Thiruvananthapuram - 695011, Kerala, India \\ Email address: \\ vijayamohan@cds.ac.in
}

To cite this article:

Vijayamohanan Pillai N.. Peak Load Pricing with Heterogeneous Technology: The Off-Peakers Too Bear the Capacity Cost. Science Journal of Energy Engineering. Vol. 2, No. 1, 2014, pp. 1-7. doi: 10.11648/j.sjee.20140201.11

\begin{abstract}
The present paper attempts at a contribution to peak load pricing theory. The general result from the traditional theory that charges the off peak consumers marginal operating costs only and the peak users marginal operating plus marginal capacity costs has already been called into question in the literature. This paper shows that if the off-peak period output is explicitly expressed in terms of capacity utilisation of that period, the result will be an off-peak price including a fraction of the capacity cost in proportion to its significance relative to total utilisation.
\end{abstract}

Keywords: Peak, Off-Peak, Pricing, Capacity Utilisation

\section{Introduction}

The literature on peak load pricing essentially emerged in response to problems faced by most public utilities, such as electricity supply industry ${ }^{1}$ and telecommunications, whose products are economically non-storable and demand is time varying. These characteristics tend to result in non-uniform utilisation of capacity. Here peak load pricing offers an indirect load management mechanism that meets the dual objectives of i) reducing growth in peak load ('peak clipping'), thus nipping the need for capacity expansion, by charging a higher peak price, and ii) shifting a portion of the load from the peak to the base load plants ('valley filling'), thereby securing some savings in peaking fuels, by charging a lower off peak price. This thus ensures an improvement in capacity utilisation as well as a cut in operating and capacity costs. The context of public utilities in such peak load problem led the economists $[1,17,11,22]$; to name a few) to model pricing rules based on maximisation of social welfare rather than profits.

The general result from the traditional theory charges the off peak consumers marginal operating costs only and the peak users marginal operating plus marginal capacity costs, since it is the on-peakers who press against capacity. Following [18], Crew and Kleindorfer [4] relax the assumption of homogeneous production capacity, and

${ }^{1}$ It is in fact the peak load problem in electricity supply that motivated much of the early work on the peak load pricing theory [6]. considers diverse technology, as efficient provision for a periodic demand generally implies an optimal plant mix of different types of capacity with different relative energy and capacity costs. They show that the traditional conclusion holds only for homogeneous plant capacity (e.g., in one plant case), and in economic loading of two or more plants, the off peak price also includes a part of capacity costs. Wenders [21] argues that the application of peak load pricing theory to the electric utility, where cost minimisation requires that heterogeneous electric generation technologies be used to meet demands of different duration, stands to modify the usual result. He shows that with heterogeneous technology, off peak marginal cost prices almost always should include some marginal capacity costs a la marginal capacity cost savings under certain circumstances. But Joskow [12], in his comment on the paper, clarifies that these off peak prices can also be rewritten in terms of marginal energy costs only, in a way to validate the traditional result. Panzar [13], on the other hand, proposes that the usual peak load pricing result is due to the fixed proportions technological assumption employed in the traditional theory and is not a consequence of the fundamental nature of the peak load problem. He shows in particular that in a framework of neoclassical technology of short run decreasing returns to scale, consumers in all periods make a positive contribution toward the cost of capital inputs.

It goes without saying that the equity norms are violated in the traditional peak load pricing, whereby off-peak users pay 
no capacity charges, but are supplied output out of the capacity, ${ }^{2}$ 'bought/hired' by the on-peakers. True, the accounting sense of pricing is satisfied here (total cost is recouped, capacity cost being drawn from on-peakers); but its 'cross-subsidisation' stands inimical to fairness in tariffing. Weintraub [20] sees a 'free ride' problem in the peak load pricing, and argues that 'The P-H [peak hour] buyers have every reason to claim that the 'property' - the capital facility - is theirs, that they pay for it and that others can use it only at a price in order to reduce the net price to them - the P-H users. An outcome which allocates common costs to only the peak-users thus has some disquieting equity features which go to the roots of private property, income distribution, and the diffusion of consumer well-being.' [20: 512]. He therefore suggests 'an alternative solution', ('output maximisation') that is, setting prices such that peak plus offpeak output are maximised, subject to the constraint that costs are covered. For him it is possible that peak price is greater than or less than or equal to off-peak price (p. 513). But this would detract from the peak load pricing as a load management strategy: the peak price must always be greater than the off-peak one in order to improve capacity utilisation at a desirable uniform level through 'peak clipping' and 'valley filling'; at the same time it should be so structured as to ensure equity concerns by apportioning capacity costs, (which are common to all periods), to both the peak and offpeak users by their importance relative to total use. The present paper seeks such a solution, especially in the context of electricity supply.

There is yet another, technical, reason why off-peakers also should bear capacity charges. Power consumption rises over time, with increasing number of consumers and of electrical gadgets in use, as well as increasing intensity of their use. Additional plants are required to meet not only the rising peak load but also the expanding base load. Thus the additional capacity costs involved in installing new base load plants must be borne by all the consumers, irrespective of the period of use, as the base load plants are continuously used in both the periods. This is why in the diverse technology framework, implied in economical load scheduling, off-peakers are also charged a part of capacity costs. As already stated, in [4] and [21] this appears in terms of an expression for capacity and running cost savings in line with the logic of optimum plant mix, without yielding a practical rate structure in a format like that of peak price. Our methodology does yield such a one.

In the next section we present the traditional peak load pricing theory and discuss the implications of the

\footnotetext{
${ }^{2}$ It should be correctly (and rightly) pointed out here that the traditional theory looks forward in the right sense of marginal cost pricing to the cost of additional capacity required to satisfy the on-peakers, but ignores to look backward in the true sense of cost accounting to the actual cost of that part of capacity that the off-peakers use. Remember, the additional capacity thus 'bought' by the peakers in turn become available for the off-peakers also but at no cost, though fairness allocates a part of the capacity cost to them also in proportion to their importance in total use. It is in this context of equity considerations that the theory appears unfair.
}

assumptions involved. Section 3 introduces, with a view to facilitating our further discussion, some of the important techno-economic characteristics of an electric utility. Section 4 presents the modified peak load pricing model. The last section concludes the study.

\section{The Traditional Theory}

In its simplest version (e.g., [17]), the model assumes two independent loads, each of equal length, in a demand cycle (a 'day') denoted by $\mathrm{Do}(\mathrm{Po})$ and $\mathrm{Dp}(\mathrm{Pp})$. The peak load problem results from the assumption that $\mathrm{qo}<\mathrm{qp}=$ capacity, where qtis the quantity demanded in period $\mathrm{t}(\mathrm{t}=$ peak (p); off-peak (o)); this means that Do(Po) lies everywhere below $\mathrm{Dp}(\mathrm{Pp})$. The independent demand denotes that one period price has no effect on the other period quantity demanded. There is only one type of plant available for generation (homogeneous technology), and investment is always forthcoming for sufficient capacity to meet demand. The supply costs are linear $-\beta$ being the per unit capacity charges per 'day' and $b$, the per unit operating charges per period. Then a unit output demanded in peak period costs $b+\beta$, as demand presses against capacity, necessitating additions, and that in off-peak period costs only $b$, as no additional capacity is required. ${ }^{3}$ Figure 1illustrates this two-period solution. The two prices are optimal in thesense of maximising the net social welfare. Any other price would involve a net loss in welfare; for example, at price $P_{p}^{\prime}$, there would be a net welfare loss of $\mathrm{ABC}$. A formal discussion of the solution is given below.

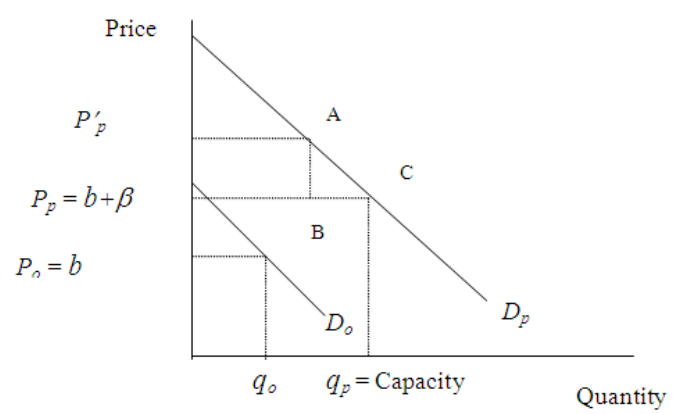

Fig 1. Traditional peak load pricing

The traditional peak load pricing rule is obtained from the first-order condition for the maximisation of net social welfare, defined by

$$
\mathrm{W}=\sum_{t} \int_{0}^{q_{t}} P_{t}\left(y_{t}\right) d y_{t}-C\left(q_{t}\right)
$$

\footnotetext{
${ }^{3}$ Note that this case refers to what is known as Steiner's 'firm peak case'. Steiner also considers what is called 'shifting peak case' that results as the pricing serves its purpose of load management. The low off-peak price induces and the high peak price discourages consumption such that the loads tend to shift. At the resulting price-output points, capacity is fully utilised in both the periods, and the capacity cost is shared in proportion to the relative strength of the loads, thus determining different prices. This case is out of our consideration here.
} 
where $P_{t}\left(q_{t}\right)$ is the inverse demand function, assumed to be periodically independent; $C\left(q_{t}\right)$ is the total cost, composed of capacity and operating components, i.e.,

$$
\mathrm{C}\left(\mathrm{q}_{\mathrm{t}}\right)=\beta q_{p}+b \sum_{t=o, p} q_{t}
$$

where $q_{p}$ is the peak period demand (= capacity), $q_{o}$, offpeak period demand (< capacity), $\beta$ and $b$ are the per unit capacity cost per cycle (e. g., a day) and operating cost per period respectively, and $t$ denotes different periods (say, peak $(p)$ and off-peak $(o))$. Maximisation of the net social benefits yields the following optimal peak $\left(P_{p}\right)$ and off-peak $\left(P_{o}\right)$ prices:

$$
\mathrm{P}_{\mathrm{o}}=\mathrm{b} \text {, and } \mathrm{P}_{\mathrm{p}}=\mathrm{b}+\beta
$$

Thus the on-peakers are to bear the entire capacity costs, and the off-peakers are favoured by charging them only operating costs.

It is generally recognised that the peak load problem emerges from the (oft-factual) assumption that $q_{\text {off-peak }}<$ $q_{\text {peak }}=$ capacity, but it is less understood that the solution results from the implicit assumption of the independence of off-peak output from capacity, and thus, as Panzar [13: 521] rightly points out, has nothing to do with the 'fundamental nature of the peak load problem'. It is traditionally assumed that whenever a unit of capacity is installed at a cost $\beta$, it becomes available for demand in all periods; off-peak demand also is met from this capacity; yet this relationship is not explicitly incorporated into the cost equation. And thus the off-peak price comes out without the capacity cost component! Herein lies the significance of equity concerns in the sense of [20]. It can be shown that if the off-peak period output is explicitly expressed in terms of capacity utilisation of that period, the result will be an off-peak price including a fraction of the capacity cost in proportion to its significance relative to total utilisation. This would appear as a general case, irrespective of the nature of generation technology, that is, even when there is only one plant, in contrast to [4] and [21]. The objective of this paper is thus to illustrate this as follows.

\section{Some Techno-Economic Characteristics of Electric Utility}

As already noted, electric utility is characterised by an economically non-storable product and a periodically fluctuating load. The load on a utility is the varying sum of all the residential, commercial, and industrial loads, each varying by time of day in its own way. A typical (smoothed) system load curve (as a plot of load, in kilowatt $(\mathrm{kW})$, against the time at which it occurs) is given in the first part of Fig. 2. There is a pronounced valley in the curve during early morning hours and a peak in the evening. The area under a (daily) chronological load curve measures the total energy consumption during the day, evaluated by $\int_{0}^{24}(k W) d t$, expressed in kilowatt-hour $(\mathrm{kWh})$ terms. From the load curve is derived the load duration curve (LDC), by rearranging all the loads of the chronological curve in the order of descending magnitude; thus it plots the load against the number of hours (or duration, $\theta$ ) during the day for which it occurs. A typical LDC also is shown in Fig. 2. Note that the areas under the chronological curve and the corresponding LDC are equal. Annual LDC is generated from the aggregation of all the daily load curves, and is used for planning purposes, which we will consider later on.

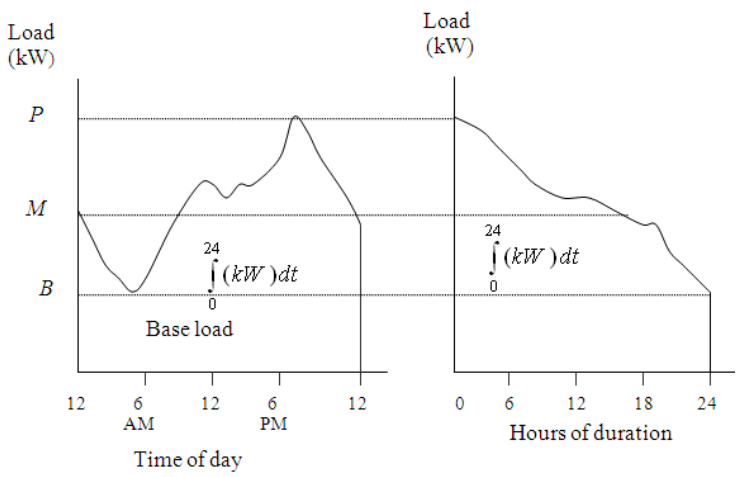

Fig 2. Chronological load curve and the derived load duration curve

The cost of supplying electricity to consumers may be divided into demand and energy costs, comparable to the common industrial classification of fixed and variable costs. Demand (or load or capacity) costs are the capacity related costs for generation, transmission and distribution, and vary with the quantity of plant and equipment and the associated investment. Energy (or unit or output) costs are those which vary directly with the quantity of units (kilowatt-hours) generated. They are largely made up of the costs of fuel, fuel handling and labour. The $\beta$ in our earlier discussion roughly represents the demand costs and $b$, the energy costs. Thus determination of $b$ is straightforward, once number of units of energy generated is known. On the other hand, $\beta$ is determined on the basis of pro-rating of the annuitised cost of installing and maintaining the plant over its useful life. Thus, if the basic cycle is one year and the life of a plant of $100 \mathrm{~kW}$ capacity is 25 years, then $\beta$ will be equal to $1 / 100$ th of the annuity sufficient to maintain and replace the plant after 25 years. ${ }^{4}$

An important concept that has an overwhelming bearing on common cost allocation is load factor (LF), defined as the ratio of the average load (in kilowatts) to the peak or maximum load during a given period (say, a year). If we disregard reserve margin, assuming capacity as equal to peak load, then the ratio (LF) yields capacity factor (CF), a measure of capacity utilisation, rather than demand variability as implied in the former. Plant load factor (PLF) defined in the same vein measures capacity utilisation of a given plant. It goes without saying that cost per unit 
(kilowatt-hour) generated is inversely related to capacity utilisation and thus to LF. That is, at cent per cent LF, installed capacity is put to the best possible use, and the maximum possible amount of energy is produced during a given period; capacity cost distributed over this maximum amount of energy would be a minimum in this respect. On the other hand, at a low LF, the same capacity cost is spread over a less number of units generated, yielding higher unit cost. Thus a poor LF implies cost inefficiency also. It is this techno-economic characteristic that we make use of in our model; that is, the capacity cost is distributed on an average basis according to the PLF.

Given this background, let us now turn to the optimum planning of plant mix. With reference to Fig.2, suppose that the peak demand on the system is $P \mathrm{~kW}$. If there is only one generating plant in the station, with a capacity equal to the peak load, then the prime mover and generator will be running under-loaded most of the time, thus rendering the operation uneconomical. A better method is to divide the load into three parts, referred to as base load $(B)$, intermediate load $(M)$ and peak load $(P)$, as shown in Fig. 2, each being supplied from separate plants. Thus the base load plant, with a capacity of $B \mathrm{~kW}$, is run continuously for all the time (i.e., on full load), and the peak load plant, with a capacity of $P-M \mathrm{~kW}$, only for a short time. Between these two is the duration of operation of the intermediate load plant, with a capacity of $M-B \mathrm{~kW}$.

The most economical operation of an electric utility requires that the plant having the minimum operating cost be used to meet the base load, e.g., run-of-river-flow-type (or reservoir-type) hydroelectric plant or nuclear power plant, and that the plant with the highest operating cost, to supply the peak load, e.g., gas turbine plant or pumpedhydro plant. The logic is simple - the total running cost will be a minimum, if the plants are operated inversely to their running costs; remember the base load plants are run for the longest time (with full load, i.e., at cent per cent PLF) and the peak load plants for the shortest time (at lower PLF). Evidently, the total operating cost will be a minimum, when a low-running-cost plant (rather than a high-cost one) is used as the base load plant. At the same time, optimum planning also requires that the capacity cost of the base load plant be the highest and that of the peak load plant, the lowest, as it is so in practice: nuclear or hydropower plants are much costlier to install than the gas turbines. The cost minimisation in this respect evidently follows from the inverse cost-PLF relationship, explained above. It should also be pointed out here that in actual practice, hydro- or diesel-power plant is used as peak load plant, since these sets are quick to respond to load variations, as the control required is only for the prime mover, whereas in steamturbine plant, control is needed for the turbines as well as for the boilers.

The significance of PLF in determining the most economical plant scheduling, that has much to do with the structuring of optimum tariffing, has, however, not so far been recognised in peak load pricing literature. And precisely this technical inadequacy has been the source of the error in the usual peak load pricing result, which supplies to the off-peakers free of capacity cost. Once the capacity utilisation factor during a particular period is accounted for in an optimum tariff structuring, then the corresponding portion of the capacity cost is automatically attributed to that period. This we show below.

\section{The Modified Peak Load Pricing Model}

As usual, the problem is to maximise the net social welfare, given by

$$
\mathrm{W}=\sum_{t} \int_{0}^{D_{t}} \theta_{t} P_{t}\left(y_{t}\right) d y_{t}-C(D, Q)
$$

where $D_{t}$ is demand in period $t(t=1, \ldots, T), P_{t}\left(D_{t}\right)$ is the inverse demand function, assumed to be periodically independent, ${ }^{5} \theta_{t}$ denotes the duration of period $t$, and $C(D, Q)$ represents total cost as a function of demand and capacity during the given cycle. We follow the heterogeneous technology specification of [5]: there are $m$ different plants $(j=1, \ldots, m)$, having constant operating cost $b_{j}$ (per kilowatt-hour per period) and capacity cost $\beta_{j}$ (per kilowatt per cycle, say, year); therefore the total cost is:

$$
\mathrm{C}=\sum_{t} \sum_{j} \theta_{t} b_{j} q_{j t}+\sum_{j} \beta_{j} Q_{j}
$$

where $q_{j t}$ is power output (in $\left.\mathrm{kW}\right)^{6}$ of plant $j$ in period $t$ and $Q_{j}$, capacity of plant $j$ (in $\mathrm{kW}$ ).

This maximisation is subject to:

$$
\begin{gathered}
\sum_{j} q_{j t}=D_{t}, \quad \forall t,\left(\text { dual variables } \lambda_{t}\right) \\
k_{j t} Q_{j}-q_{j t}=0, \quad \forall j, t, \quad\left(\text { dual variables } \gamma_{j t}\right) \\
D_{t} \geq 0, \quad q_{j t} \geq 0, \quad Q_{j} \geq 0, \quad \forall j, t,
\end{gathered}
$$

where $k_{j t}=q_{j t} / Q_{j}$, as implied in (7). The first constraint (6) requires that demand be met in each period, and the second (7) that output of each plant in each period be equal to the corresponding capacity that is actually utilised. Implied in the latter is the condition that output should not exceed capacity; but it qualifies the usual capacity constraint in terms of capacity utilisation, and thus rules out the possibility of off-peak output being independent of capacity, as explicitly specified so far in the literature. And this is our basic point of departure from the tradition.

5 Note that the demands are periodically independent. We can, following [16], specify interdependent demands, in which case we will have a line-integral formulation of gross surplus. Such a welfare function is well defined when certain 'integrability conditions' are satisfied (also see [7: $19-22]$, which is possible when demands in different periods are independent. Then the line integral specification of gross welfare becomes just the sum of simple integrals, as in equation (4).

6 Thus $\theta t$ qjt represents energy (in kilowatt-hour) of plant $j$ during period $t$. 
Now the Lagrangian (L) from (4) - (8) is:

$$
L=W+\sum_{t} \lambda_{t}\left(\sum_{j} q_{j t}-D_{t}\right)+\sum_{t} \sum_{j} \gamma_{j t}\left(k_{j t} Q_{j}-q_{j t}\right)
$$

Assuming strictly positive output (or $D_{t}>0$ ), at the optimal solution, the Kuhn-Tucker conditions for the above maximisation problem are:

$$
\begin{gathered}
\theta_{t} P_{t}\left(D_{t}\right)=\lambda_{t}, \quad \forall t \\
\lambda_{t}-\theta_{t} b_{j}-\gamma_{j t} \leq 0, \quad q_{j t} \geq 0, q_{j t}\left(\lambda_{t}-\theta_{t} b_{j}-\gamma_{j t}\right)=0 ; \quad \forall j, t \\
\sum_{t} \gamma_{j t} k_{j t}-\beta_{j} \leq 0, Q_{j} \geq 0, Q_{j}\left(\sum_{t} \gamma_{j t} k_{j t}-\beta_{j}\right)=0, \forall j \\
\gamma_{j t} \geq 0, \quad \gamma_{j t}\left(k_{j t} Q_{j}-q_{j t}\right)=0, \quad \forall j, t
\end{gathered}
$$

Also note that with independent demands, $L$ (in 9) is strictly concave, and the above conditions, (10) - (13), are necessary and sufficient for maximisation.

Now, let us find the optimum prices for the two periods, peak and off-peak ( $t=$ peak, $p$; off-peak, $o$ ), first in the case of the traditional framework of homogeneous technology (i.e., only one plant; $j=1$ ). From (10) and (11), we get

$$
\theta_{t} P_{t}=\theta_{t} b_{1}+\gamma_{1 t}, \quad \forall t=p, o
$$

Consideration of (7) along with (13) requires that $\gamma_{1 t}>0$ always; i.e., the (modified) capacity constraint is always binding, since, as we have already discussed, some capacity is utilised in the base period also. Hence, we have to substitute in (14) for the shadow price from (12) for $Q_{1}>0$. Since this capacity is used in both the periods, though in different degrees depending on $k_{1 t}$ (such that $k_{1 o} Q_{1}=q_{1 o}=$ $D_{\mathrm{o}}<k_{1 p} Q_{1}=q_{1 p}=D_{p}$ at the optimum), the corresponding capacity cost is to be distributed over the whole range of output of both the periods and then apportioned to each period in proportion to its significance. The first task (of capacity cost distribution over total output) may better be captured by dividing the unit capacity cost, $\beta_{1}$, by the sum of the capacity utilisationactors, $k_{1 t}$, of the two periods. ${ }^{7}$ Consideration of (12) for $Q_{1}>0$ then lends enough sense to equate this with the shadow price of the modified capacity constraint (7). ${ }^{8}$ That is,

$$
\gamma_{1 t}=\frac{\beta_{1}}{\sum_{t=p, o} k_{1 t}} \equiv \frac{\beta_{1}}{k_{1}} \equiv \beta_{1}^{\prime}
$$

Where $k_{1}$. is the sum of $k_{1 t}$ over peak and off-peak periods. Thus we have the two optimum prices (per kilowatt-hour) as:

\footnotetext{
${ }^{7}$ Remember $k_{1 t}=q_{1 t} / Q_{1}$.

${ }^{8}$ Note that this implies that the shadow price of the modified capacity constraint (7) for any plant is the same across all time periods, $\gamma_{j o}=\gamma_{i p}$, but as (12) specifies, its attributed share varies across time according to the corresponding capacity utilisation.
}

for peak period:

$$
P_{p}=b_{1}+\frac{\beta_{1}^{\prime}}{\theta_{p}}
$$

and for off-peak period:

$$
P_{o}=b_{1}+\frac{\beta_{1}^{\prime}}{\theta_{o}}
$$

Since the peak time duration $\left(\theta_{p}\right)$ is much shorter (though $k_{1 p}$ is the maximum), the unit capacity cost contribution to peak period price (per kilowatt-hour) will be much higher, and hence the peak period price will be much greater than the off-peak price, as required. Also note, with reference to (16) and (17), that the sales revenue from the output of plant $j$ during time $t$, is given by $P_{t} \theta_{t} q_{j t}=b_{j} \theta_{t} q_{j t}+\alpha_{j t} \beta_{j} Q_{j}$, where $\alpha_{j t}=k_{j t} / k_{j \bullet}=q_{j t} / q_{j}$ is the plant's output share during time $t$ (where $q_{j}=\sum_{t} q_{j t}$ ), such that the total revenue from any plant $j$ during any time $t$ covers the corresponding total (energy and capacity) costs.

Thus we find that both the on-peakers and the offpeakers contribute to capacity cost recovery, in inverse proportion to their load duration. It should be stressed that our result contradicts all the earlier studies in the homogeneous technology framework, which have toed the tradition of sparing the off-peakers from capacity charges. Also note that the load management strategy of the peak load pricing dominates here over the minimum cost allocation principle associated with PLF. Again, this capacity cost allocation to the off-peakers does not follow the usual marginal cost principle, but just corresponds to a fairness principle in the sense of [20] in accounting for capacity use that occurs in both the periods, though the additional capacity is occasioned by only the peak users. This result is unique in the homogeneous technology case only. In the diverse technology framework, based on economical load scheduling, it is the marginal cost principle itself that matters; that is, by accounting for additional capacity in both peak and base load, as explained earlier. We now turn to this case, with $j=2$ plants.

Suppose that plant 1 (say, hydropower plant) has lower marginal operating (and higher marginal capacity) costs than plant 2 (say, gas turbine). Optimal load scheduling requires that plant 1 be run as base load plant, and plant 2 to meet peak load. Evidently, the off-peak price is related to the costs of plant 1 and peak price to that of plant 2, in line with the marginal cost principle. Since plant 1 is used continuously in both peak and off-peak periods, we have $\gamma_{1 t}$ $>0, t=o, p$, such that

$$
k_{1 o} Q_{1}=q_{1 o}=k_{1 p} Q_{1}=q_{1 p}=D_{o}>0
$$

that is, plant 1 continues to supply $q_{1 p}=D_{o}$ units in the peak period also. On the other hand, plant 2 is used only in peak period, such that $\gamma_{2 o}=0, k_{2} .=k_{2 p}$, and meets the additional peak requirements: 


$$
k_{2 p} Q_{2}=q_{2 p}=D_{p}-D_{o}>0
$$

Then, we have:

for off-peak period:

$$
P_{o}=b_{1}+\frac{\beta_{1}^{\prime}}{\theta_{o}}
$$

And for peak period:

$$
P_{p}=b_{2}+\frac{\beta_{2}}{k_{2 p} \theta_{p}} \equiv b_{2}+\frac{\beta_{2}^{\prime}}{\theta_{p}}
$$

Remember $b_{1}<b_{2}$, but $\beta_{1}>\beta_{2}$. Peak duration is much shorter than off-peak duration; while the peak load plant normally operates at low load factor, the base load plant is run at full capacity, such that $k_{1 o}=k_{1 p}>k_{2 p}$. Thus (20) and (21) appear incomparable. However, we can rewrite (20) in terms of capacity and running cost savings in the context of optimal plant mix a la [4] and [21], and prove that the offpeak price is lower than the peak price in the given operating regime, as required.

From (10) and (11), we get for $j=1$ and $t=o$,

$$
\theta_{o} P_{o}=\theta_{o} b_{1}+\gamma_{1 o}
$$

from (10), (11) and (12), and noting that $k_{1 o}=k_{1 p}$,

$$
\gamma_{1 o}=\beta_{1} / k_{1 o}-\left(P_{p}-b_{1}\right) \theta_{p}
$$

Therefore, we have ${ }^{9}$

$$
P_{o}=b_{1}\left(1+\frac{\theta_{p}}{\theta_{o}}\right)+\frac{\beta_{1}}{k_{1 o} \theta_{o}}-\left(b_{2}+\frac{\beta_{2}}{k_{2 p} \theta_{p}}\right) \frac{\theta_{p}}{\theta_{o}}
$$

The logic for this is as follows. Given the operating regime in (18) and (19), the cost of meeting an additional unit of load in off-peak period can be minimised by increasing plant 1 capacity by one unit, involving a marginal cost of $b_{1} \theta_{o}+\beta_{1} / k_{1 o}$ and reducing plant 2 capacity by one unit yielding a marginal cost saving equal to $b_{2} \theta_{p}+\beta_{2} / k_{2 p}$, the cost that would have been incurred, had plant 2 been used instead (which in turn is equal to $P_{p} \theta_{p}$ ); since the additional unit of plant 1 is used in peak period also, it involves an extra cost of a fraction of its running cost, $\left({ }^{b_{1}} \theta_{p}\right)$. Hence the expression (24).

Now let us prove that this price (24) lies below the peak load price (21) in the given operating regime. Since plant 1 is used at full load in both the periods, its marginal cost $\left(m c_{1}\right)$ of supplying one unit is: $b_{1}\left(\theta_{o}+\theta_{p}\right)+\beta_{1} / k_{1 o}$ (from (11) - (12) and noting $\gamma_{j t}>0$ and $k_{j o}=k_{j p}$ ). Optimal plant mix requires that this be less than the corresponding

\footnotetext{
${ }^{9}$ Note that the expression is equivalent to that for off-peak price given by Crew and Kleindorfer[4], assuming two equal duration periods and disregarding PLF terms.
}

marginal cost of plant $2 \quad\left(m c_{2}\right)$, given by $b_{2}\left(\theta_{o}+\theta_{p}\right)+\beta_{2} / k_{2 p}$, since otherwise plant 1 would not be required at all. This inequality $\left(m c_{1}<m c_{2}\right)$ yields the required bounds: $b_{1}<P_{o}<b_{2}<P_{p}$ at the optimum. At the same time note that since plant 2 is used to meet the peak load, it must be cheaper than plant 1 to do so; that is, $m c_{2 p}=$ $b_{2} \theta_{p}+\beta_{2} / k_{2 p}<m c_{1 p}=b_{1} \theta_{p}+\beta_{1} / k_{1 p} ;\left(k_{j o}=0\right)$. Thus we have the following bounds at the optimum in general: $b_{1}<$ $P_{o}<b_{2}<P_{p}<m c_{1 p} / \theta_{p}$.

An important property of our pricing model is that it easily lends itself to generalisation in practical application. With reference to (20) and (21), note that it is the unit (energy and capacity) costs of the marginal plant that go into the rate structure - plant 1 is used at the margin in the off-peak period and plant 2 in the peak period, though the former, being the base load plant, also is in use during the peak period. This technical characteristic helps us generalise the pricing rule for a scenario of diverse technology $(j=1, \ldots, m)$, with multiple periods $(t=1, \ldots, T)$ as:

$$
P_{t}=b_{j}+\frac{\beta_{j}}{k_{j} \bullet \theta_{t}} \equiv b_{j}+\frac{\beta_{j}^{\prime}}{\theta_{t}}
$$

where $\beta_{j}^{\prime} \equiv \beta_{j} / k_{j}$, and $k_{j \bullet} \equiv \sum_{t} k_{j t}$, and the parameters are those of the marginal plant in use at time $t$. Remember the base load plant, $(j=1)$, is continuously run in all the periods, the medium load plants, in peak and intermediate periods only, and the peak load plant, $(j=m)$, in peak period only, such that $k_{m}=k_{m p}$.

\section{Conclusion}

The present paper has attempted at a contribution to peak load pricing, in both theory and application. The general result from the traditional theory that charges the off peak consumers marginal operating costs only and the on-peak users marginal operating plus marginal capacity costs, since it is the on-peakers who press against capacity has already been called into question. It has also been shown that the equity norms are violated in the traditional peak load pricing, whereby off-peak users pay no capacity charges, but are supplied output out of the capacity, 'bought/hired' by the on-peakers. Theoretical attempts at modification have proved that the traditional conclusion holds only for homogeneous plant capacity (e.g., in one plant case), and in economic loading of two or more plants, the off peak price also includes a part of capacity costs. However, this appears in terms of an expression for capacity and running cost savings in line with the logic of optimum plant mix, without yielding a practical rate structure in a format like that of peak price. Our methodology does yield such a one.

It has been traditionally assumed that whenever a unit of capacity is installed at a cost, it becomes available for demand in all periods; off-peak demand also is met from this capacity; yet this relationship has not been explicitly 
incorporated into the cost equation. And thus the off-peak price has come out without the capacity cost component! This paper, however, shows that if the off-peak period output is explicitly expressed in terms of capacity utilisation of that period, the result will be an off-peak price including a fraction of the capacity cost in proportion to its significance relative to total utilisation. This would appear as a general case, irrespective of the nature of generation technology, that is, even when there is only one plant.

An important property of our pricing model is that it easily lends itself to generalisation in practical application. Another important merit of our method is its amenability to customergroup-wise tariffs structuring. The marginal capital cost may be apportioned, following the average method of common cost allocation, among the different customer classes.

\section{References}

[1] Boiteux, Marcel, (1949) 'Peak Load Pricing', translated in Journal of Business, April 1960, 33: 157-79; reprinted in Nelson, James R. (ed.) Marginal Cost Pricing in Practice, Prentice-Hall Inc., Englewood Cliffs, N. J. 1964.

[2] Boiteux, Marcel, and Stasi, P. (1964) 'The Determination of Costs of Expansion of an Interconnected System of Production and distribution of Electricity', in Nelson, J. R. (ed.) Marginal Cost Pricing in Theory and Practice, Prentice-Hall Inc., Englewood Cliffs, N. J.

[3] Chicchetti, C. W., Gillen, W. and Smolensky, P. (1977) The Marginal Cost and Pricing of Electricity, Ballinger Publishing Co., Cambridge.

[4] Crew, M. A. and Kleindorfer, P. R. (1971) 'Marshall and Turvey on Peak Load or Joint Product Pricing', Journal of Political Economy, 79 (6), Noveember - December: 136977.

[5] Crew, M. A. and Kleindorfer, P. R. (1975) 'Optimal Plant Mix in Peak Load Pricing', Scottish Journal of Political Economy, 22 (3), November: 277-91.

[6] Crew, M. A. and Kleindorfer, P. R. (1976) 'Peak Load Pricing with a Diverse Technology', The Bell Journal of Economics, 7 (1), Spring: 207-31.

[7] Crew, M. A. and Kleindorfer, P. R. (1979) Public Utility Economics, Macmillan, London.

[8] Davidson, Ralph K. (1955) Price Discrimination in Selling
Gas and Electricity, Johns Hopkins Press, Baltimore.

[9] DeSalvia, D. N. (1969) 'An Application of Peak Load pricing', Journal of Business, October: 458-76.

[10] Doran, John J., et al., (1973) Electric Utility Cost Allocation Manual, National Association of Regulatory Utility Commissioners, Washington D.C.

[11] Hirshleifer, Jack (1958) 'Peak Loads and Efficient Pricing: Comment', Quarterly Journal Of Economics, 72: 451- 62.

[12] Joskow, Paul L. (1976) 'Contributions to the Theory of Marginal Cost Pricing', The Bell Journal of Economics, 7 (1), Spring: 197-206.

[13] Panzar, John C. (1976) 'A Neo-Classical Approach to Peak Load Pricing', The Bell Journal of Economics, 7 (1), Spring: 521-530.

[14] Pillai, N. Vijayamohanan (2001) Electricity Demand Analysis and Forecasting - the Tradition is Questioned! Working Paper No. 312, February, Centre for Development Studies, Thiruvananthapuram.

[15] Pillai, N. Vijayamohanan (2002) 'Power Sector Reforms in Kerala', invited paper presented in a special session of the Indian Economic Association $85^{\text {th }}$ Annual Conference in Thiruvananthapuram on $28^{\text {th }}$ December, 2002.

[16] Pressman, I. (1970) 'A Mathematical Formulation of the Peak-Load Pricing Problem', Bell Journal of Economics and Management Science, 1 (2), Autumn: 304-26.

[17] Steiner, P. O., (1957) 'Peak Loads and Efficient Pricing', Quarterly Journal of Economics, 71, November: 585-610.

[18] Turvey, Ralph (1968) 'Peak Load Pricing', Journal of Political Economy, 76, February: 101-13

[19] Turvey, Ralph (1969) 'Marginal Cost', Economic Journal, 79, June: 282-99.

[20] Weintraub, Sidney (1970) 'On Off-Peak Pricing: An Alternative Solution', Kyklos, 23 (3): 501-518.

[21] Wenders, John T. (1976) 'Peak Load Pricing in the Electric Utility Industry', The Bell Journal of Economics, 7 (1), Spring: $232-41$.

[22] Williamson, Oliver E. (1966) 'Peak Load Pricing and Optimal Capacity under Indivisibility Constraints', American Economic Review, 56, September: 810-27.

[23] Williamson, Oliver E. (1974) 'Peak Load Pricing: Some Further Remarks', The Bell Journal of Economics and Management Science, 5 (1), Spring: 223-28. 